\title{
A COMPARATIVE ANALYSIS OF SPECTRAL INFORMATION EXTRACTION ALGORITHMS FOR TARGET DETECTION OF HYDROTHERMAL ALTERATION ZONES USING ASTER SATELLITE IMAGE DATA
}

\author{
A. J. Abubakar ${ }^{1 *}$, M. Hashim ${ }^{2}$, A. B. Pour ${ }^{3}$, Y. Saleh ${ }^{1}$ \\ ${ }^{1}$ Department of Geography, Faculty of Science, Kaduna State University P. M. B. 2339, Kaduna, Nigeria \\ - abusuhay177@gmail.com \& yusou90@gmail.com \\ ${ }^{2}$ Geoscience and Digital Earth Centre (INSTeG), Research Institute for Sustainable Environment (RISE), \\ Universiti Teknologi Malaysia (UTM) - mazlanhashim@utm.my \\ ${ }^{3}$ Korea Polar Research Institute (KOPRI), Songdomirae-ro, Yeonsu-gu, Incheon 21990, Republic of Korea \\ - amin.beiranvand@kopri.re.kr
}

KEY WORDS: ASTER, Hydrothermal Alteration, Geothermal, SAM, LSU

\begin{abstract}
:
The focus of this paper is to evaluate the performance of the Advanced Spaceborne Thermal Emission and Reflection Radiometer (ASTER) data for target detection of hydrothermal alteration zones associated with geothermal (GT) springs as proxy for narrowing areas of interest. The study employed the Per-pixel Spectral Angle Mapper (SAM) and the Sub-pixel Linear Spectral Unmixing (LSU) algorithms for spectral information extraction by using the ASTER satellite image data. In both cases, image endmember spectra specifically for kaolinite, alunite, and illite and calcite zones were selected and extracted by using the Analytical Imaging and Geophysics (AIG)-developed processing methods. The results of the analysis show that both SAM and LSU discriminated targets of interest better when employing image spectra and poorly when using library spectra. However, the Per-pixel SAM is unsuitable for target detection and more suited where the objective of the investigation is to classify whole scene and not particular targets as in this case. The LSU was found to be effective for discriminating alterations associated with the thermal springs especially where image endmember spectra are employed for analysis, thus recommended for prefeasibility mapping of GT related resources.
\end{abstract}

\section{INTRODUCTION}

\subsection{General Instructions}

Mapping and identifying prospective geothermal (GT) resources can be challenging. This is especially the case in subtle systems not easily identifiable using conventional survey techniques (Abubakar et al., 2019). This signifies the need for more investigations in such unique regions and their identification using state of the art techniques of remote sensing and spectroscopy (Abubakar et al., 2017). The present study is thus premised on the need to improve and refine methods of mapping unconventional GT targets in order to fully realize the potentials of GT resources as a competitive renewable energy alternative with diverse exploitative uses (Lund and Boyd, 2016).

Hydrothermal alteration mapping can serve as a proxy technique for identification of indicator minerals for characterization of potential GT systems (Renaut et al., 2017). However, hydrothermally altered minerals rarely occur purely to match its corresponding library spectra in all situations and in peculiar environmental settings because rock alteration vary from one region to another depending on prevailing conditions which results in unique hydrothermal alteration (Masoumi et al., 2017). Consequently variable mineral mixtures may result which could affect the diagnostic spectral reflectance or emittance characteristics of endmembers of interest (Hosseinjani and Tangestani, 2011).
This study explored the mapping of subtle GT systems by exploring the utility of image endmembers spectra extracted from regions of interest (ROIs) which have been field validated and laboratory verified for spectral analysis, as compared to corresponding library spectra. The study essentially evaluated the ASTER (VNIR-SWIR) data for mapping hydrothermal alteration zones related to GT systems, specifically thermal springs by analyzing SAM and LSU spectral information extraction algorithms on ASTER image data. The study area is the Yankari Park, an unexplored sparsely vegetated savanna region in north eastern Nigeria characterized by a number of thermal hotsprings including; Wikki, Mawulgo, Gwana and Dimmil. Field and GPS surveys conducted have indicated several hydrothermally altered rocks in the vicinity and surrounding sampled areas of the Wikki and Mawulgo thermal springs (Abubakar et al., 2017).

\subsection{Study Area and Geology}

The study area is Yankari Park, located within Latitude 9.75000N, and Longitude 10. 50000E in Bauchi State, northeastern Nigeria (Figure 1). It covers about 2,244 square kilometers (866 sq. mi). Thermal springs in the Park include; Dimmil, Gwana, Mawulgo and Wikki. Geologically, it is within the Kerri formation characterized by Neogene to Mesozoic older sedimentary rocks which is composed of sandstone, silt stones, kaolinites, grits and clays (Abubakar et al., 2019). The processes around the springs are influenced by the nature of 
fractured sediments and permeability within the quartzite caused by intergranular pore spaces together with the fracturing of the relatively competent quartzite (Osagie, 2008). Consequently, kaolinite, ironstones, carbonate, quartz and sulfates, which are the hydrothermal alteration minerals predominantly identified, are associated with surface manifestations of the hot springs in the study area (Ajakaiye et al., 1988).

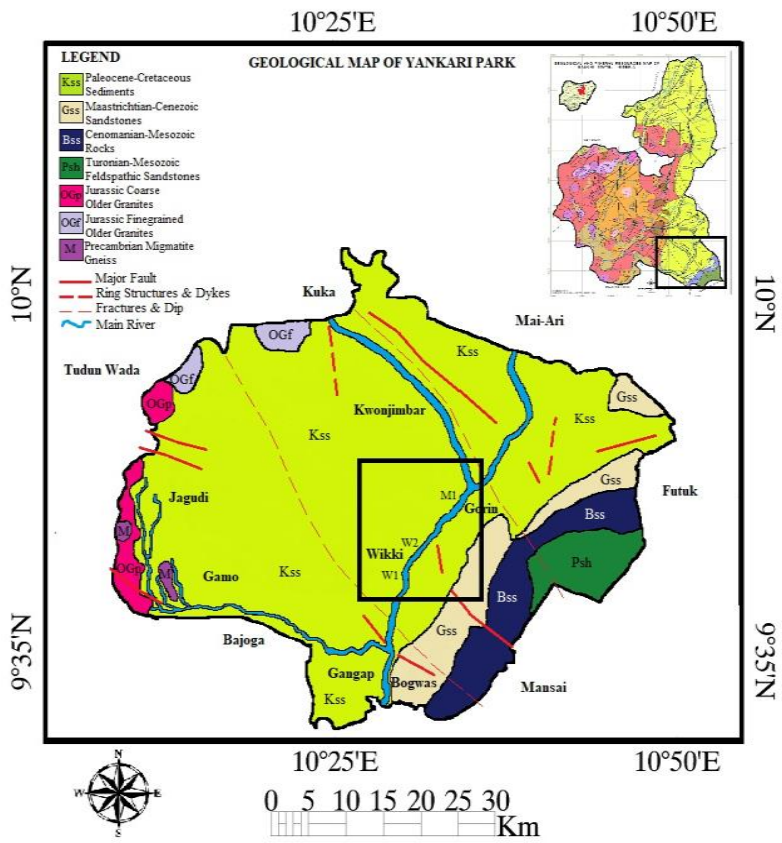

Figure 1. Geological Map of Yankari Park Showing the Study Area

\section{MATERIALS AND METHODS}

\subsection{ASTER data}

Four ASTER level 1T (AST_L1T, path/raw, 187/53) scenes acquired on 01/012003 and 25/01/2006 covering the Yankari Park study area were obtained from the LPDAAC data pool. Using ENVI classic mosaic georeferenced tool, the image scenes were mosaicked, to have a complete scene. The ASTER level 1T is a Precision Terrain Corrected Registered At-Sensor Radiance data that has been geometrically rectified, and turned to a north-up UTM $32 \mathrm{~N}$ projection with WGS 84 Datum (Abrams et al., 2015). ASTER is a multispectral instrument which acquires data in 14 bands using 3 sensors in the VNIR (0.52-0.86um), SWIR (1. 60-2.40um) and TIR (8.12-11.65um) portions of EMS at $15 \mathrm{~m}, 30 \mathrm{~m}$ and $90 \mathrm{~m}$ spatial resolutions respectively (Abrams et al., 2015)

\subsection{Atmospheric Corrections of acquired data}

The ASTER data is corrected using the Fast Line-of-site Atmospheric Analysis of Spectral Hypercubes (FLAASH) (Perkins et al., 2012). The objective of FLAASH is to eliminate atmospheric attenuations caused by molecular and particulate scattering and absorption from the 'radiance-at-sensor' measurements in order to retrieve 'reflectance-at-surface' values (Pour et al., 2018). The ASTER radiance data was imported into ENVI 5.1, preprocessing calibration utilities and the FLAASH option was chosen as atmospheric correction, uncorrected
ASTER data is used as input radiance image, appropriate radiance scale factor for VNIR/SWIR and output reflectance file/root name for the FLAASH files selected. ASTER was chosen as sensor type. From global attributes; scene center time and date were retrieved. The ASTER Meta data file was also used to retrieve several parameters including; Latitude and Longitude values, sensor altitude, ground elevation, pixel size, satellite flight overpass date and time. Tropical atmospheric model was chosen and other variables such as aerosol model and retrieval, spectral polishing and initial visibility were used as defaults (Research Systems, 2008). The FLAASH atmospheric correction is then applied and the resulting reflectance image saved for subsequent analysis.

The summary of data characteristics of ASTER is shown in Table 1.

\begin{tabular}{|l|l|}
\hline Satellite Instrument & Terra/ ASTER \\
\hline Spectral Range $(\mu \mathrm{m})$ & $0.52-0.86(\mathrm{VNIR})$ \\
& $1.6-2.4$ (SWIR) \\
& $8.1-11.7$ (TIR) \\
& 0 \\
\hline Panchromatic band & 3 (stereo) \\
\hline Visible Near Infrared (VNIR) & 0 \\
\hline Cirrus clouds band & 6 \\
\hline Shortwave Infrared (SWIR) band & 5 \\
\hline Thermal Infrared (TIR) & $15,30,90 \mathrm{~m}$ \\
\hline Spatial resolution & 60 km \\
\hline Swath width & Discrete \\
\hline Spectral coverage & N/A \\
\hline Pan band resolution & yes \\
\hline Stereo & 14 \\
\hline Total band numbers & 16 days \\
\hline Temporal resolution & \\
\hline
\end{tabular}

Table 1. ASTER data characteristics

\subsection{The AIG-Developed Methods}

The Advanced Imaging \& Geophysics (AIG) processing method was used to analyze the data and select endmembers and for subsequent spectral information extraction (Kruse et al., 2003). The ENVI 5.1 Spectral Hourglass procedure was used and includes; Data dimensionality reduction using minimum noise fraction (MNF), Locating purest pixels using the Pixel Purity Index (PPI), Identification and selection of endmember spectra using spectral library \& mean image spectra i.e. from regions of interest (ROIs) verified in the field during GPS survey, Fractional abundance estimation of endmembers using perpixel-SAM and sub-pixel-LSU respectively. Finally, the determination of accuracy of processing results using root mean square error estimation and confusion matrix. The AIGDeveloped analysis aids in reducing the data both spectrally and spatially to help adequately locate, identify and characterize a few class of materials or features that can be used to describe the datasets (Van der Meer et al., 2012). 
2.3.1 Spectral Angle Mapper (SAM): SAM is a whole pixel classification method used for comparing image spectra (an unknown) to a known reference spectra e.g. from spectral libraries, ASCII files (Boardman and Kruse, 1994; Kruse, 2012). In this study, the reference spectra is chosen from USGS spectral library and by extraction of image spectra using the Analytical Imaging and Geophysics (AIG)-developed methods (Kruse et al., 2003). The SAM techniques estimates the similarity between the image spectrum and the reference spectrum by calculating the angle between the two spectra while treating them as vectors in n-dimensional space (Research Systems, 2008). The result of the SAM is shown in Figure 2.

2.3.2 Linear Spectral Unmixing (LSU): The LSU algorithm is used to determine the actual proportion or abundance of pure endmember (class) materials within a pixel. The energy recorded by a remote sensing detector is a function of the amount of energy reflected or emitted by the materials within the Instantaneous Field Of View (Research Systems, 2008). ENVI 5.1 was used to determine the distribution and relative abundance of the indicator minerals as endmembers in the ASTER subset image. The LSU relies on the assumption that the reflectance at each pixel of the ASTER image is a linear combination of the reflectance of each endmember present within the pixel (Boardman and Kruse, 2011).

\section{RESULTS AND DISCUSSIONS}

\subsection{Results of SAM using image spectra}

The SAM was first applied to ASTER subset scene Wikki ROI ( $375 \times 335$ pixels), using the image spectra as reference. The extracted image spectra are designated as; kaolinite-alunite, muscovite-illite, calcite-chlorite representing; argillic, phyllic, propylitic alteration zones respectively. The SAM was done using a default radian angle of 0.10 . The resulting SAM class image as shown in figure 2(a) indicates argillic, phyllic and propylitic alterations in red, blue and green respectively. The whole scene was classified into the 3 End member (EM) classes, without clear alteration points as identified in the field. Iteratively, the radian angle was reduced to 0.04 and 0.02 as in figure 2 (b \& c). Results in (b), clearly discriminates phyllic and argillic alterations at $\mathrm{W} 1$, however, propylitic alteration appear exaggerated when compared with the NDVI image in figure 2 d. Using the SAM radian angle of 0.02 (figure $2 \mathrm{c}$ ) gives a conservative result with fewer pixels as alteration zones at verified points $\mathrm{W} 1$ and $\mathrm{W} 2$. This further established that using smaller radian angles estimates pixels with the best match (Van Der Meer, 1999). This was possible using the image spectra. However, the overall accuracy and kappa coefficient of all the 3 results were calculated as shown in Tables 2,3 \& 4 respectively. It was observed that the 0.10 angle result has an overall accuracy and kappa of $85.99 \%$ and 0.784 , the 0.04 angle has $71.17 \%$ and 0.594 , while 0.02 angle has $33.81 \%$ and 0.243 respectively. This signifies that, although the radian angle can be reduced to identify the best matching pixels resulting in a more conservative classification, the results are however poor as shown by the Error matrix and Kappa coefficient.
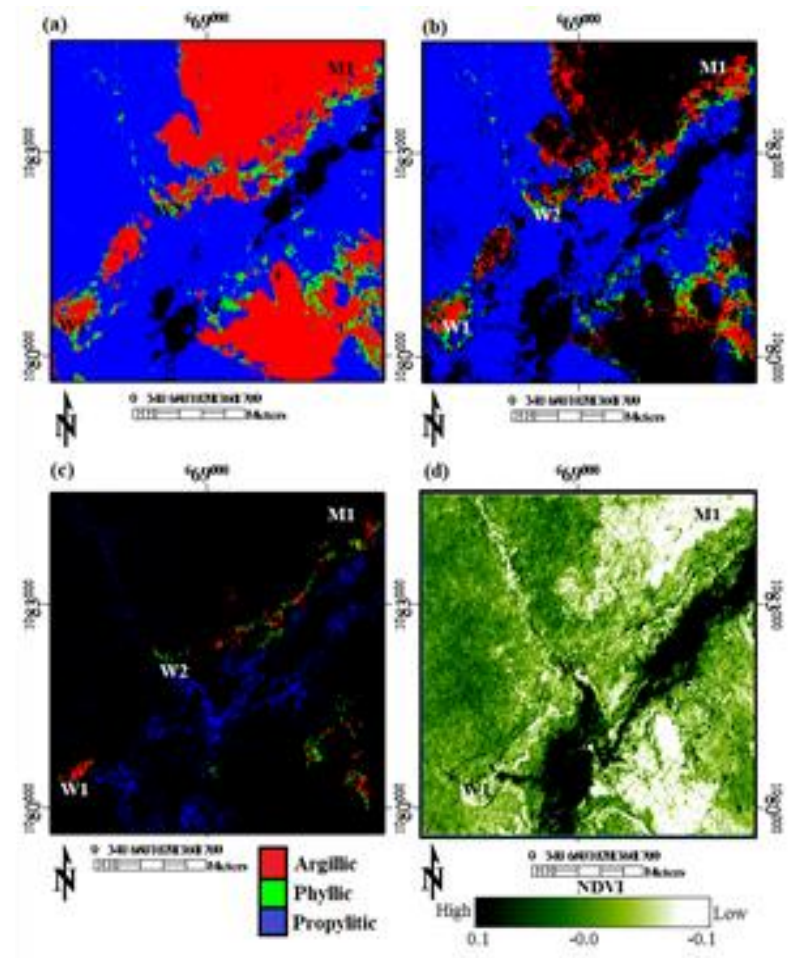

Figure 2. Results of SAM at Wikki ROI using image spectra showing 3 alteration zones at radian angles (a) 0.10 (b) 0.04 (c) 0.02 (d) NDVI

\begin{tabular}{|c|c|c|c|c|c|}
\hline $\begin{array}{l}\text { Reference } \\
\text { data }(\%)\end{array}$ & & & & & \\
\hline Class & $\begin{array}{l}\text { Kao- } \\
\text { alu \% }\end{array}$ & $\begin{array}{l}\text { Mus- } \\
\text { ilt \% }\end{array}$ & $\begin{array}{c}\text { Cal-chl } \\
\%\end{array}$ & Total & $\begin{array}{c}\text { Users } \\
\text { accuracy }\end{array}$ \\
\hline Unclassified & 0.00 & 170 & 0.00 & 0.48 & inches \\
\hline $\begin{array}{l}\text { Kao-alu- } \\
\text { w2 (\%) }\end{array}$ & 89.70 & 38.07 & 0.00 & 34.62 & 68.84 \\
\hline $\begin{array}{l}\text { Mus-ilt-w2 } \\
(\%)\end{array}$ & 10.30 & 60.23 & 0.00 & 19.81 & 86.18 \\
\hline $\begin{array}{l}\text { Cal-chl-w2 } \\
(\%)\end{array}$ & 0.00 & 0.00 & 100 & 45.09 & 100 \\
\hline Total & 100 & 100 & 100 & 100 & \\
\hline $\begin{array}{l}\text { Producers } \\
\text { accuracy }\end{array}$ & 89.70 & 60.23 & 100 & & \\
\hline
\end{tabular}

Table 2. Error matrix for SAM at 0.10 angle (image spectra) Overall Accuracy $=85.9 \% ;$ Kappa Coefficient $=0.78$ 


\begin{tabular}{|c|c|c|c|c|c|}
\hline \multicolumn{6}{|l|}{$\begin{array}{l}\text { Reference } \\
\text { data }(\%)\end{array}$} \\
\hline Class & $\begin{array}{l}\text { Kao- } \\
\text { alu \% }\end{array}$ & $\begin{array}{l}\text { Mus- } \\
\text { ilt \% }\end{array}$ & $\begin{array}{c}\text { Cal-chl } \\
\%\end{array}$ & Total & $\begin{array}{c}\text { Users } \\
\text { accuracy }\end{array}$ \\
\hline Unclassified & 1.82 & 20.45 & 22.14 & 16.26 & inches \\
\hline $\begin{array}{l}\text { Kao-alu- } \\
\text { w2 (\%) }\end{array}$ & 89.70 & 36.36 & 0.00 & 34.14 & 69.81 \\
\hline $\begin{array}{l}\text { Mus-ilt-w2 } \\
(\%)\end{array}$ & 8.48 & 43.18 & 0.00 & 14.49 & 84.44 \\
\hline $\begin{array}{l}\text { Cal-chl-w2 } \\
(\%)\end{array}$ & 0.00 & 0.00 & 77.86 & 35.10 & 100 \\
\hline Total & 100 & 100 & 100 & 100 & \\
\hline $\begin{array}{l}\text { Producers } \\
\text { accuracy }\end{array}$ & 89.70 & 43.18 & 77.86 & & \\
\hline
\end{tabular}

Table 3. Error matrix for SAM at 0.04 angle (image spectra) Overall Accuracy $=71.1 \%$; Kappa Coefficient $=0.59$

\begin{tabular}{|c|c|c|c|c|c|}
\hline \multicolumn{6}{|l|}{$\begin{array}{l}\text { Reference } \\
\text { data }(\%)\end{array}$} \\
\hline Class & $\begin{array}{l}\text { Kao- } \\
\text { alu \% }\end{array}$ & $\begin{array}{l}\text { Mus- } \\
\text { ilt \% }\end{array}$ & $\begin{array}{c}\text { Cal-chl } \\
\%\end{array}$ & Total & $\begin{array}{c}\text { Users } \\
\text { accuracy }\end{array}$ \\
\hline Unclassified & 29.70 & 69.32 & 74.64 & 61.19 & inches \\
\hline $\begin{array}{l}\text { Kao-alu- } \\
\text { w2 (\%) }\end{array}$ & 67.27 & 14.77 & 0.00 & 22.06 & 81.02 \\
\hline $\begin{array}{l}\text { Mus-ilt-w2 } \\
(\%)\end{array}$ & 3.03 & 15.91 & 0.00 & 5.31 & 84.85 \\
\hline $\begin{array}{l}\text { Cal-chl-w2 } \\
(\%)\end{array}$ & 0.00 & 0.00 & 25.36 & 11.43 & 100 \\
\hline Total & 100 & 100 & 100 & 100 & \\
\hline $\begin{array}{l}\text { Producers } \\
\text { accuracy }\end{array}$ & 67.27 & 15.91 & 25.36 & & \\
\hline
\end{tabular}

Table 4. Error matrix for SAM at 0.02 angle (image spectra) Overall Accuracy $=33.8 \%$; Kappa Coefficient $=0.24$

\subsection{Results of SAM using library spectra}

Result of SAM analysis using the library spectra for kaolinitealunite1.txt.C2 (red), muscovite-illite1.txt.C2 (green) and calcite-chlorite2.txt.C2 (blue) as endmembers using the default radian angle of 0.10 is shown in figure 3(a), which indicates that the SAM discriminated only argillic alteration as red (Kaolinite-alunite.txt.C2) and the phyllic and propylitic alterations were unclassified. Iteratively, the threshold angle was reduced to 0.04 and 0.02 as done initially, however, in both cases the result was without any coherent class image which indicates a poor characterization of the scene by the corresponding library spectra. The classified argillic zone (kaolinite-alunite.txt.C2-red) also mostly correspond to sparsely vegetated zones in the scene as shown in the NDVI image in fig. 3(b) and did not adequately discriminate known alteration zones as identified in the field around $\mathrm{W} 1, \mathrm{~W} 2$ and M1 points.
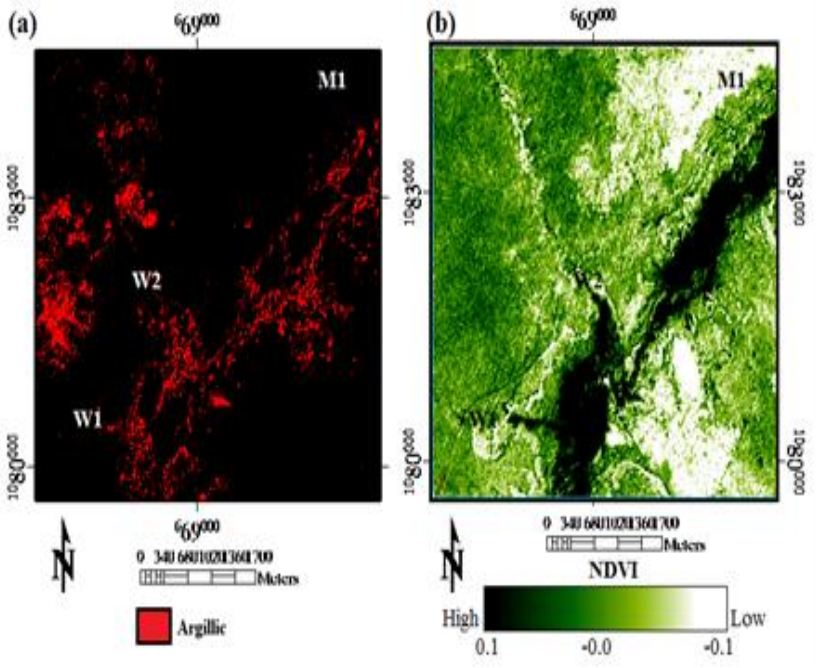

Figure 3. Results of SAM at Wikki ROI using library spectra showing alteration zones. (a) 0.10 default radian angle (b) NDVI image at Wikki ROI showing vegetated-exposed zones

The accuracy assessment for the SAM result using library spectra is shown in table 5 which indicates an overall accuracy of $100 \%$ and Kappa of 1.00 respectively.

\begin{tabular}{|c|c|c|c|c|c|}
\hline $\begin{array}{l}\text { Reference } \\
\text { data }(\%)\end{array}$ & & & & & \\
\hline Class & $\begin{array}{l}\text { Kao- } \\
\text { alu \% }\end{array}$ & $\begin{array}{l}\text { Mus- } \\
\text { ilt \% }\end{array}$ & $\begin{array}{c}\text { Cal-chl } \\
\%\end{array}$ & Total & $\begin{array}{c}\text { Users } \\
\text { accuracy }\end{array}$ \\
\hline Unclassified & 100 & 0.00 & 0.00 & 94.34 & $\begin{array}{c}\text { inches } \\
100\end{array}$ \\
\hline $\begin{array}{l}\text { Kao-alu- } \\
\text { w2 (\%) }\end{array}$ & 0.00 & 100 & 0.00 & 5.66 & 100 \\
\hline $\begin{array}{l}\text { Mus-ilt-w2 } \\
(\%)\end{array}$ & 0.00 & 0.00 & 0.00 & 0.00 & 0.00 \\
\hline $\begin{array}{l}\text { Cal-chl-w2 } \\
(\%)\end{array}$ & 0.00 & 0.00 & 0.00 & 0.00 & 0.00 \\
\hline Total & 100 & 100 & 0.00 & 100 & \\
\hline $\begin{array}{l}\text { Producers } \\
\text { accuracy }\end{array}$ & 100 & 100 & 0.00 & 0.00 & \\
\hline
\end{tabular}

Table 5. Error matrix for SAM at 0.10 angle (library spectra) Overall Accuracy $=100 \%$; Kappa Coefficient $=1.00$

In comparison with the initial analysis using image spectra above (figure 2), it is observed that per-pixel SAM analysis using image spectra gives a coherent image class, however, it does not identify targets but discriminates almost the whole scene including the unwanted background which includes sparsely vegetated zones as observed using the NDVI image. Moreover, estimating the accuracy using error matrix and kappa simply calculates the accuracy on the basis of the class including the unwanted background. Thus an image in (figure 2a) using radian angle 0.10 has a better accuracy despite mapping unwanted areas, while reducing the angle to 0.04 gives a better result (figure $2 b$ ), iterative reduction of the angle to 0.02 reduces the overall accuracy of the results (table 4 ). In comparison, the use of library spectra produces an even poorer discrimination. This signifies that the per-pixel SAM is not suitable for spectral mapping of particular targets (Van Der Meer, 1999), but rather all the elements in a scene and not 
favourable for GT indicator alteration mapping for identifying targets.

\subsection{Results of LSU using image spectra}

The complete sub-pixel unmixing LSU algorithm is first applied to evaluate use of image spectra as reference at Wikki roi. The result of the LSU is a grayscale abundance image one for each endmember. Thus the 3 endmember images are loaded as RGB and overlaid on a grayscale image indicating pixel abundance as shown in figure 4(a). The sub-pixel algorithm was observed to discriminate the argillic (red) $(2.16 \mu \mathrm{m})$, phyllic (green) $(2.209 \mu \mathrm{m})$ and propylitic (blue) $(2.35 \mu \mathrm{m})$ alteration zones clearly, probably due to the separate wavelength regions used to differentiate the 3 regions and the spectral fidelity of ASTER bands in the SWIR portion which is effective in mapping hydroxyl-bearing minerals in the SWIR subsystems (Van Der Meer, 1999; van der Meer et al., 2018).
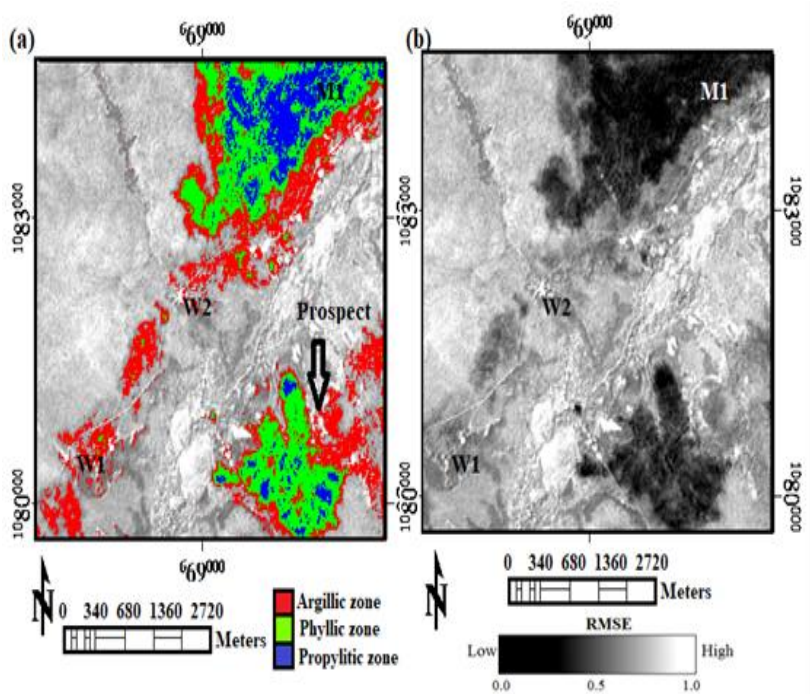

Figure 4: (a) LSU subpixel abundance image using image spectra (Wikki roi). (b) RMSE for image in (a)

The result also identified areas verified in the field at W1, W2 and M1 which are exposed altered zones as observed in the NDVI image of the subset area (see figure 3b). The RMSE image in figure 4(b) is used to assess accuracy of the result which shows errors as bright pixels and dark pixels as good fit (Van Der Meer, 1999). The RMSE image indicates a good agreement with the abundance image as areas discriminated as alteration zones correspond to dark pixels in the error image signifying possible valid detections.

\subsection{Results of LSU using library spectra}

The result of the LSU using library spectra for kaolinitealunite1.txt.C2 (red), muscovite-illite1.txt.C2 (green) and calcite-chlorite2.txt.C2 (blue) representing argillic, phyllic, and propylitic alteration zones respectively, gave an abundance image as shown in figure 5(a). The abundance image similarly compares with the result in figure 4(a) above, especially for argillic (red) zone. It however, over exaggerates the abundances of propylitic (blue) zone which are mostly marsh land and scrub vegetation as observed in the NDVI image in figure 3(b).
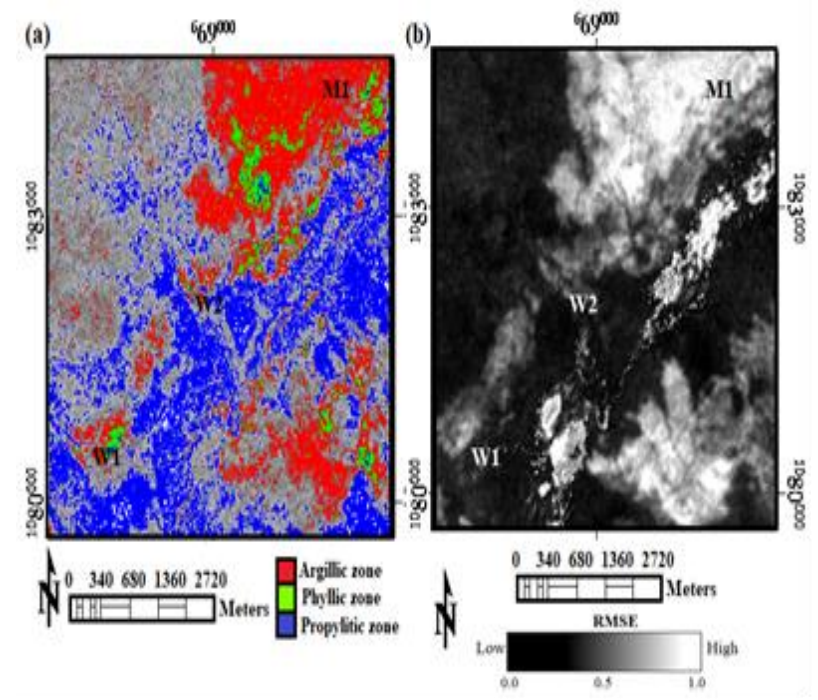

Figure 5: (a) LSU subpixel abundance image using library spectra (Wikki roi). (b) RMSE image for image in (a)

The RMSE image in figure 5(b) indicates that most of the pixels discriminated by the LSU algorithm as argillic and phyllic zone are errors as shown by the bright pixels, while the propylitic zone is well discriminated according to the RMSE. However, the areas identified as propylitic are errors signifying that the library spectra endmembers did not match the actual features in the scene. Thus, the subpixel abundance image in figure $5(a)$ is not well characterized. It was observed that the result identified known altered zones especially around W1 and exaggeratedly at M1. This indicates that the library spectra did not exactly match all the features in the scene especially as shown by the RMSE image despite identifying alteration zones of interest.

\section{CONCLUSIONS}

In conclusion, the result of the analysis shows that both SAM and LSU discriminated targets of interest better when employing image spectra and poorly when using library spectra. However, the Per-pixel SAM is unsuitable for target detection of alteration areas of interest as the results are mostly misleading, moreover, employing image spectra gives coherent image with some validly identified endmember classes but with much error especially as the calculated error matrix and kappa coefficients give conflicting results, SAM is thus more suited where the objective of the investigation is to classify whole scene and not specific targets as in this case. The LSU was found to be suitable for target detection of alterations associated with thermal springs particularly by using image spectra for analysis and is recommended for prefeasibility stage mapping of subtle GT systems. The results essentially demonstrated the futility of employing only library spectra which might not in practical terms and in all situations sufficiently match all or specific features in a unique scene. Future studies are intended to evaluate the use of hyperspectral imagery data with improved spectral fidelity to investigate the algorithms for both image and library spectra. 


\section{ACKNOWLEDGEMENTS}

We are thankful to the Tertiary Education Trust Fund (Tetfund) Nigeria, for funding and supporting the registration fee for this paper. The authors also wish to acknowledge the Kaduna State University, Nigeria, Universiti Teknologi Malaysia and Korea Polar Research Institute for providing the facilities for this investigation.

\section{REFERENCES}

Abrams, M., Tsu, H., Hulley, G., Iwao, K., Pieri, D., Cudahy, T. and Kargel, J. (2015). The Advanced Spaceborne Thermal Emission and Reflection Radiometer (Aster) after Fifteen Years: Review of Global Products. International Journal of Applied Earth Observation and Geoinformation, 38, 292-301.

Abubakar, A. J. A., Hashim, M. and Pour, A. B. (2017). Identification of Hydrothermal Alteration Minerals Associated with Geothermal System Using Aster and Hyperion Satellite Data: A Case Study from Yankari Park, Ne Nigeria. Geocarto International, 1-57.

Abubakar, A. J. A., Hashim, M. and Pour, A. B. (2019). Remote Sensing Satellite Imagery for Prospecting Geothermal Systems in an Aseismic Geologic Setting: Yankari Park, Nigeria. International Journal of Applied Earth Observation and Geoinformation, 80, 157-172.

Ajakaiye, D., Olatinwo, M. and Scheidegger, A. (1988). Another Possible Earthquake near Gombe in Nigeria on the 1819 June 1985. Bulletin of the Seismological Society of America, 78(2), 1006-1010.

Boardman, J. W. and Kruse, F. A. (1994) Published. Automated Spectral Analysis: A Geological Example Using Aviris Data, North Grapevine Mountains, Nevada. Proceedings of the Thematic Conference on Geologic Remote Sensing, 1994. Environmental Research Institute of Michigan, I-407.

Boardman, J. W. and Kruse, F. A. (2011). Analysis of Imaging Spectrometer Data Using \$N \$-Dimensional Geometry and a Mixture-Tuned Matched Filtering Approach. IEEE Transactions on Geoscience and Remote Sensing, 49(11), 4138-4152.

Hosseinjani, M. and Tangestani, M. H. (2011). Mapping Alteration Minerals Using Sub-Pixel Unmixing of Aster Data in the Sarduiyeh Area, Se Kerman, Iran. International Journal of Digital Earth, 4(6), 487-504.

Kruse, F. A. (2012). Mapping Surface Mineralogy Using Imaging Spectrometry. Geomorphology, 137(1), 41-56.

Kruse, F. A., Boardman, J. W. and Huntington, J. F. (2003). Comparison of Airborne Hyperspectral Data and Eo-1 Hyperion for Mineral Mapping. IEEE Transactions on Geoscience and Remote Sensing, 41(6), 1388-1400.

Lund, J. W. and Boyd, T. L. (2016). Direct Utilization of Geothermal Energy 2015 Worldwide Review. Geothermics, 60, 66-93.

Masoumi, F., Eslamkish, T., Honarmand, M. and Abkar, A. A. (2017). A Comparative Study of Landsat-7 and Landsat-8 Data
Using Image Processing Methods for Hydrothermal Alteration Mapping. Resource Geology, 67(1), 72-88.

Osagie, E. O. (2008). Seismic Activity in Nigeria. The Pac Jour Sci and Tech, 9(2), 1-6.

Perkins, T., Adler-Golden, S., Matthew, M. W., Berk, A., Bernstein, L. S., Lee, J. and Fox, M. (2012). Speed and Accuracy Improvements in Flaash Atmospheric Correction of Hyperspectral Imagery. Optical Engineering, 51(11), 111707-1111707-7.

Pour, A. B., Park, Y., Park, T.-Y., Hong, J. K., Hashim, M., Woo, J. and Ayoobi, I. (2018). Evaluation of Ica and Cem Algorithms with Landsat-8/Aster Data for Geological Mapping in Inaccessible Regions. Geocarto International, (just-accepted), $1-64$.

Renaut, R. W., Owen, R. B. and Ego, J. K. (2017). Geothermal Activity and Hydrothermal Mineral Deposits at Southern Lake Bogoria, Kenya Rift Valley: Impact of Lake Level Changes. Journal of African Earth Sciences.

Research Systems, I. (2008). Envi Tutorials. Research Systems, Inc., Boulder, Co.

Van Der Meer, F. (1999). Iterative Spectral Unmixing (Isu). International Journal of Remote Sensing, 20(17), 3431-3436.

Van Der Meer, F., Kopačková, V., Koucká, L., Van Der Werff H. M., Van Ruitenbeek, F. J. and Bakker, W. H. (2018).

Wavelength Feature Mapping as a Proxy to Mineral Chemistry $f$ or Investigating Geologic Systems: An Example from the Rodalquilar Epithermal System. International journal of applied earth observation and geoinformation, 64, 237-248.

Van Der Meer, F. D., Van Der Werff, H. M., Van Ruitenbeek, F. J., Hecker, C. A., Bakker, W. H., Noomen, M. F., Van Der Meijde, M., Carranza, E. J. M., De Smeth, J. B. and Woldai, T. (2012). Multi-and Hyperspectral Geologic Remote Sensing: A Review. International Journal of Applied Earth Observation and Geoinformation, 14(1), 112-128. 